\title{
Vacuum Pyrolysis and Related ISRU Techniques
}

\author{
Eric H. Cardiff ${ }^{1}$, Brian R. Pomeroy ${ }^{1}$, Ian S. Banks ${ }^{1}$, Alexis Benz ${ }^{2}$ \\ ${ }^{1}$ NASA Goddard Space Flight Center, Greenbelt, MD 20771 \\ ${ }^{2}$ University of Michigan, Ann Arbor, MI, 48104 \\ 301-286-0388, Eric.H.Cardiffonasa.gov
}

\begin{abstract}
A number of ISRU-related techniques have been developed at NASA Goddard Space Flight Center. The focus, of the team has been on development of the vacuum pyrolysis technique for the production of oxygen from the lunar regolith. However, a number of related techniques have also been developed, including solar concentration, solar heating of regolith, resistive heating of regolith, sintering, regolith boiling, process modeling, parts manufacturing, and instrumentation development. An initial prototype system was developed to vaporize regolith simulants using a $\sim 1 \mathrm{~m}^{2}$ Fresnel lens. This system was successfully used to vaporize quantities of $\sim 1 \mathrm{~g}$, and both mass spectroscopy of the gasses produced and Scanning Electron Microscopy (SEM) of the slag were done to show that oxygen was produced. Subsequent tests have demonstrated the use of a larger system with a $3.8 \mathrm{~m}$ diameter reflective mirror to vaporize the regolith. These results and modeling of the vacuum pyrolysis reaction have indicated that the vaporization of the oxides in the regolith will occur at lower temperature for stronger vacuums. The chemical modeling was validated by testing of a resistive heating system that vaporized quantities of $\sim 10 \mathrm{~g}$ of MLS-1A. This system was also used to demonstrate the sintering of regolith simulants at reduced temperatures in high vacuum. This reduction in the required temperature prompted the development of a smallscale resistive heating system for application as a scientific instrument as well as a proof-of principle experiment for oxygen production.
\end{abstract}

Keywords: Vacuum pyrolysis, in situ resource utilization.

PACS: 82.30.Lp

\section{INTRODUCTION}

The in-situ production of oxygen on the lunar surface is a key part of our future in-space propulsion infrastructure. Over 20 separate technologies have been identified as being capable of producing oxygen on the lunar surface. Current NASA Administrator Mike Griffin remarked that "... the architecture can make significant use of lunar resources. At first, in all likelihood oxygen [will be] obtained by solar roasting", when he first introduced the Crew Exploration Vehicle that will be the vehicle to retum humans to the Moon (Griffin, 2005). Taylor et al. concluded from a review of available technologies that the optimal technique to produce lunar oxygen is the vacuum pyrolysis technique[1]. However, very little research has been performed to develop this technique, with most research and development efforts focusing on reduction techniques for lunar in situ resource utilization (ISRU).

Preliminary work has been performed at NASA Goddard Space Flight Center (GSFC) to advance the technology readiness level of the vacuum pyrolysis technique. This work has also lead to a number of other ISRU-related techniques, including solar concentration, solar heating of regolith, resistive heating of regolith, sintering, regolith melting, boiling, process modeling, oxygen condensation and storage, and instrumentation development.

Vacuum pyrolysis is based on the vaporization reaction of metal oxides that simultaneously reduces the oxide and produces $\mathrm{O}_{2}$. The reduced oxide can be condensed out of the low-pressure gas at temperatures below $\sim 500^{\circ} \mathrm{C}$, while the oxygen remains gaseous. The reduction of silicon dioxide is shown as an example in Equation 1.

$$
\mathrm{SiO}_{2(\mathrm{~s})} \rightarrow \mathrm{SiO}_{(\mathrm{g})}+\frac{1}{2} \mathrm{O}_{2(\mathrm{~g})}
$$

Vacuum pyrolysis avoids many of the shortcomings of other ISRU techniques. Any type of lunar regolith or rock can be used - nearly all lunar minerals will vaporize and release oxygen when sufficiently heated. This oxygen can be separated out by fractionally distilling the oxygen - the metals and reduced oxides condense while the oxygen remains as a gas. Since the process is entirely thermally controlled, a solar furnace can be used; and no materials need to be brought from the Earth once the plant is operational. 


\section{SOLAR CONCENTRATION}

Two types of solar concentration have been developed for the in situ research at NASA GSFC. The first is a Fresnel lens-based system that was used for most of the early development. A picture of the prototype system developed to test vacuum pyrolysis is shown in Figure 1. The initial prototype was very similar to the work by Senior (1993), with some significant differences. Senior used a small tungsten crucible, and examined the evolution of gas as a function of pressure. The work described in Cardiff et al. (2005) used a zirconia crucible, which is less susceptible to reacting with the effluent oxygen gas, and was able to resolve the chemical composition of the effluent in a continuously-pumped system (Cardiff, 2005).

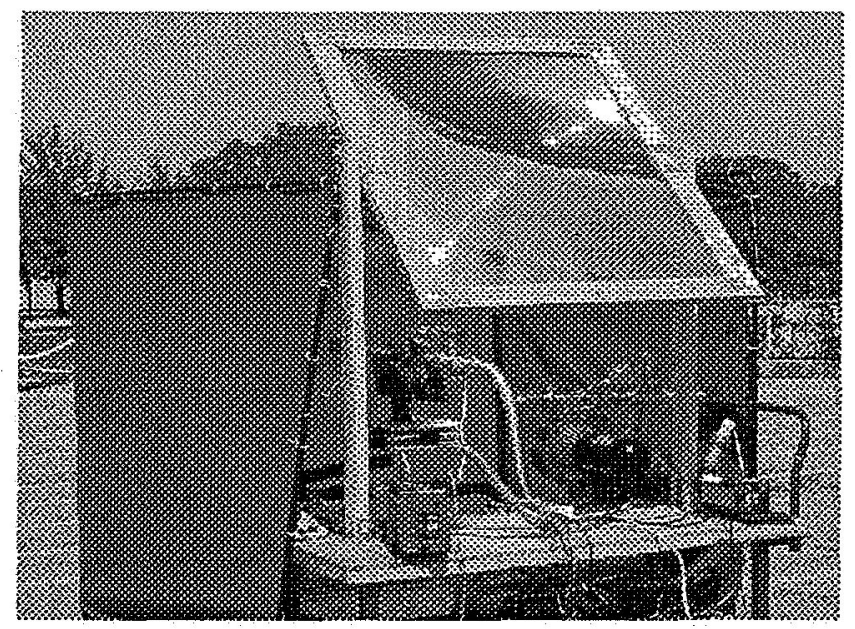

Figure 1. Picture of the prototype Fresnel system.

A second system has been built and designed to use a much larger concentration area to vaporize up to $1 \mathrm{~kg}$ of regolith. A picture of the concentrator for this system is shown here in Figure 2. The dish provides a flux of $\sim 9 \mathrm{~kW}$ into the chamber, and is located at a remote testing site of NASA GSFC.

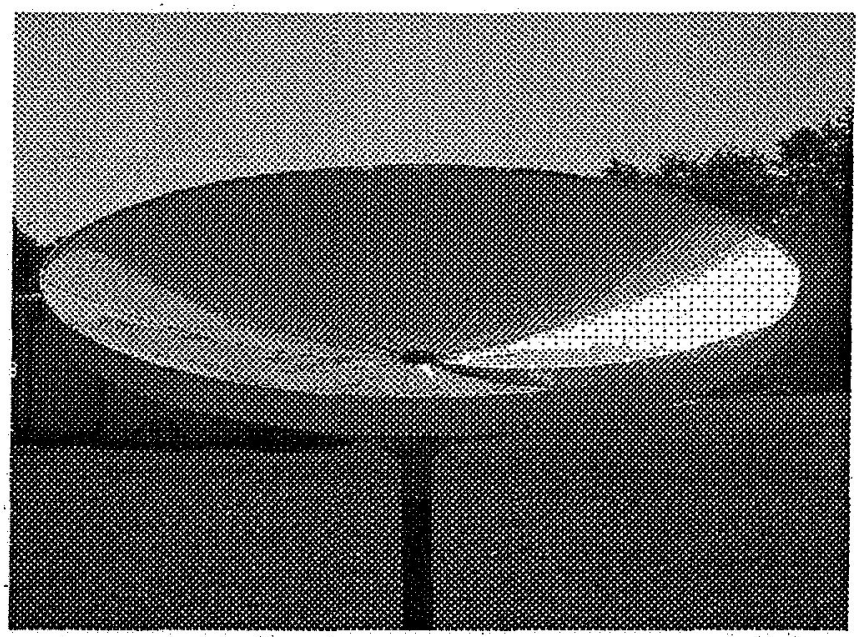

Figure 2. Reflective solar concentrator ( $3.8 \mathrm{~m}$ dish with reflective film). 


\section{RESULTS}

Several different lunar simulant materials have been vaporized and condensed in the Fresnel lens prototype system, including ilmenite, enstatite, and MLS-1A (Weiblen,1990). Results of these tests are shown in Table 1. Masses of approximately one net gram of material have been vaporized with the small prototype system. A total of twelve experimental tests were completed with the Fresnel lens pyrolysis system during this study. The temperature needed for vaporization and partial dissociation of the regolith simulants was achieved. The limited area of solar capture and many power losses caused the Fresnel system to be unable to consistently achieve the conditions necessary for dissociation. An example of the results achieved for MLS-1A and ilmenite are shown here in Figure 3.

TABLE 1. Results of 12 tests with the prototype system from 2005.

\begin{tabular}{|c|c|c|c|c|c|c|c|c|}
\hline Test & Date & Sample & $\begin{array}{c}\text { Approximate } \\
\text { Duration } \\
\text { (mins) }\end{array}$ & $\begin{array}{c}\text { Flux } \\
\left(\mathrm{W} / \mathrm{m}^{2}\right)\end{array}$ & \begin{tabular}{c|} 
Initial \\
Pressure \\
(Torr)
\end{tabular} & $\begin{array}{l}\text { Testing } \\
\text { Pressure } \\
\text { (Torr) }\end{array}$ & $\begin{array}{c}\text { Max Temp } \\
\left({ }^{\circ} \mathrm{C}\right)\end{array}$ & $\begin{array}{c}\text { Mass loss } \\
(\%)\end{array}$ \\
\hline 1 . & 10-Jan & $\mathrm{Zn}$ & 5 & - & $<1 \times 10^{-4}$ & 5 & $\sim 900$ & - \\
\hline $2 a$ & 7-Mar & $\mathrm{FeTiO}_{3}$ & 10 & 800 & $<1 \times 10^{-4}$ & $1.1 \times 10^{-1}$ & 620 & - \\
\hline $2 b$ & 7-Mar & $\mathrm{FeTiO}_{3}$ & 15 & 945 & $<1 \times 10^{-4}$ & $2 \times 10^{-2}$ & $>800$ & $16.00 \%$ \\
\hline 3 & 18-Apr & $\mathrm{FeTiO}_{3}$ & 20 & 890 & $6.0 \times 10^{-1}$ & $8 \times 10^{-1}$ & 700 & $37.00 \%$ \\
\hline 4 & 3-May & $\mathrm{MgSiO}_{3}$ & 1 & 955 & $4.4 \times 10^{-2}$ & $4.4 \times 10^{-2}$ & 548 & $0.05 \%$ \\
\hline 5 & 6-Jun & $\mathrm{MgSiO}_{3}$ & 30. & 940 & $1.4 \times 10^{-1}$ & $2.3 \times 10^{-1}$ & 1072 & $0.92 \%$ \\
\hline 6 & 16-Jun & $\mathrm{Al}_{2} \mathrm{O}_{3}$ & 20 & 950 & $1.4 \times 10^{-1}$ & 3 & 1800 & - \\
\hline 7 & 17-Jun & $\mathrm{FeTiO}_{3}$ & 67 & 975 & $2.3 \times 10^{-1}$ & 3.20 & 1867 & $0.47 \%$ \\
\hline 8 & 12-Jul & $\mathrm{MgSiO}_{3}$ & 30 & 960 & 7 & 10 & 1100 & $10.66 \%$ \\
\hline 9 & 27-Jul & $\mathrm{FeTiO}_{3}$ & 30 & 795 & $6.6 \times 10^{-2}$ & 1 . & & $0.73 \%$ \\
\hline 10 & 2-Aug & $\mathrm{FeTiO}_{3}$ & 39 & 880 & 1.4 & 1.4 & 1436 & $0.37 \%$ \\
\hline 11 & 25-Aug & MLS-1a & 52 & 1005 & $9.6 \times 10^{-2}$ & $1.4 \times 10^{-1}$ & 1474 & $10.10 \%$ \\
\hline 12 & 17-Nov & MLS-1a & 9 & 992 & $7 \times 10^{-3}$ & $1 \times 10^{-2}$ & 684 & \\
\hline
\end{tabular}
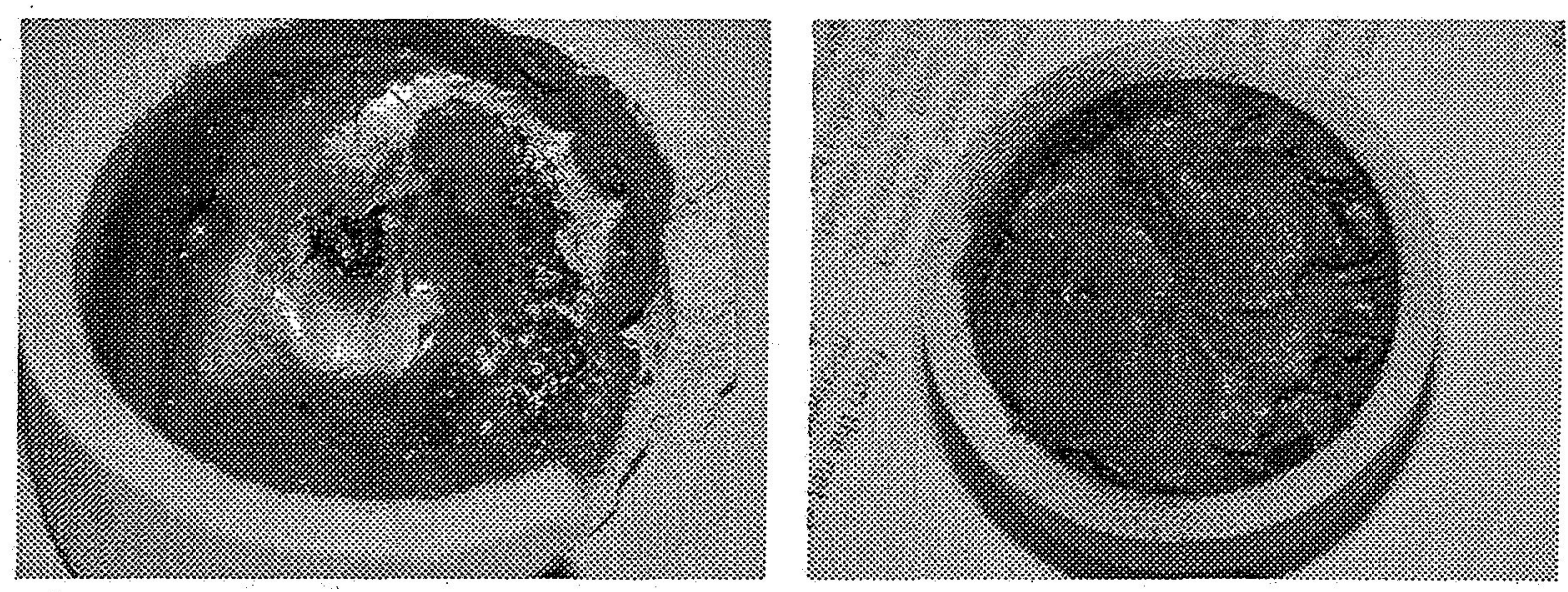

Figure 3. Pictures of partially vaporized MLS-1A (left) and ilmenite (right) from the prototype system.

An MKS Residual Gas Analyzer (RGA) was used to measure the composition of the gas effluent from the vaporization. The chamber pressure in the prototype system was too high to operate the RGA directly in the flow. The RGA is limited to operating at pressures below $10^{-5}$ Torr, therefore a leak valve was used in conjunction with a turbopump downstream of the leak valve to measure the composition of the effluent. The RGA was only used for the last test with the MLS-1A. Although the conditions during the test did not provide many periods of high 
intensity sunlight, the RGA did measure an increase in relative partial pressure of oxygen in the gas flow when the simulant was observed to boil, as shown in Figure 4. This oxygen increase also occurred simultaneously with an increase in the partial pressure of species with an atomic mass unit of 28. Unfortunately, the RGA cannot resolve between silicon and nitrogen, but this increase is consistent with the vaporization of silicon from MLS-1A. The partial pressure of water (atomic mass of 18) did not increase, which also indicates the oxygen is not atmospheric, but rather is due to vaporization and dissociation.

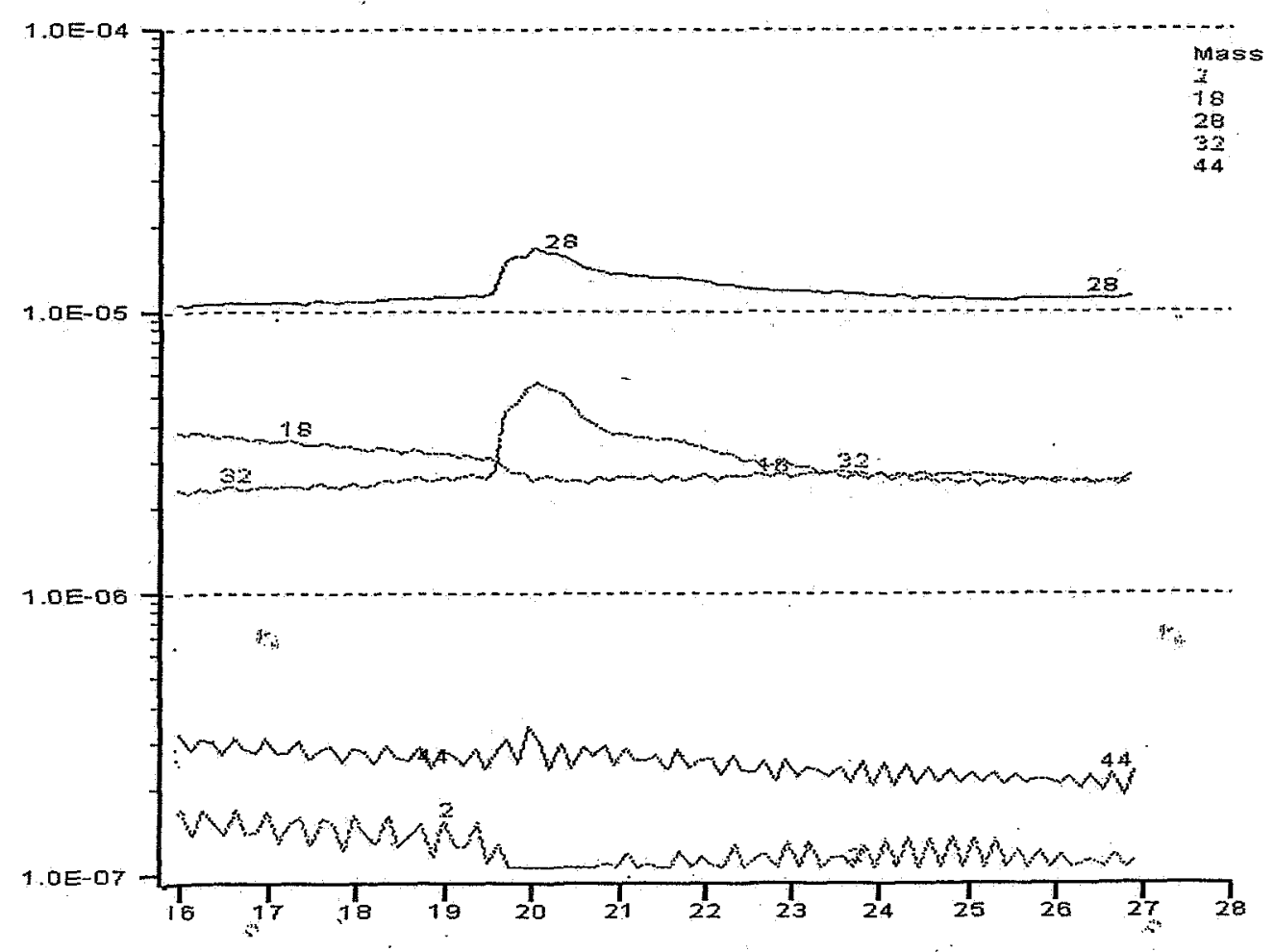

Figure 4. Residual gas analysis from test 12.

Preliminary testing of the condensation system shows that the condensation will occur within a few centimeters of the crucible. Condensation was done with passive cooling on pieces of witness material above the surface of the crucible. Scanning Electron Microscope (SEM) analysis of the slag remaining in the chamber from the prototype system tests has shown reduced oxygen at the surface of the remaining sample, indicating that there is net oxygen production. A comparison of the chemical composition of the surface of the ilmenite shown in Figure 3 (right) before (above) and after (below) vaporization is shown in Figure 5. 

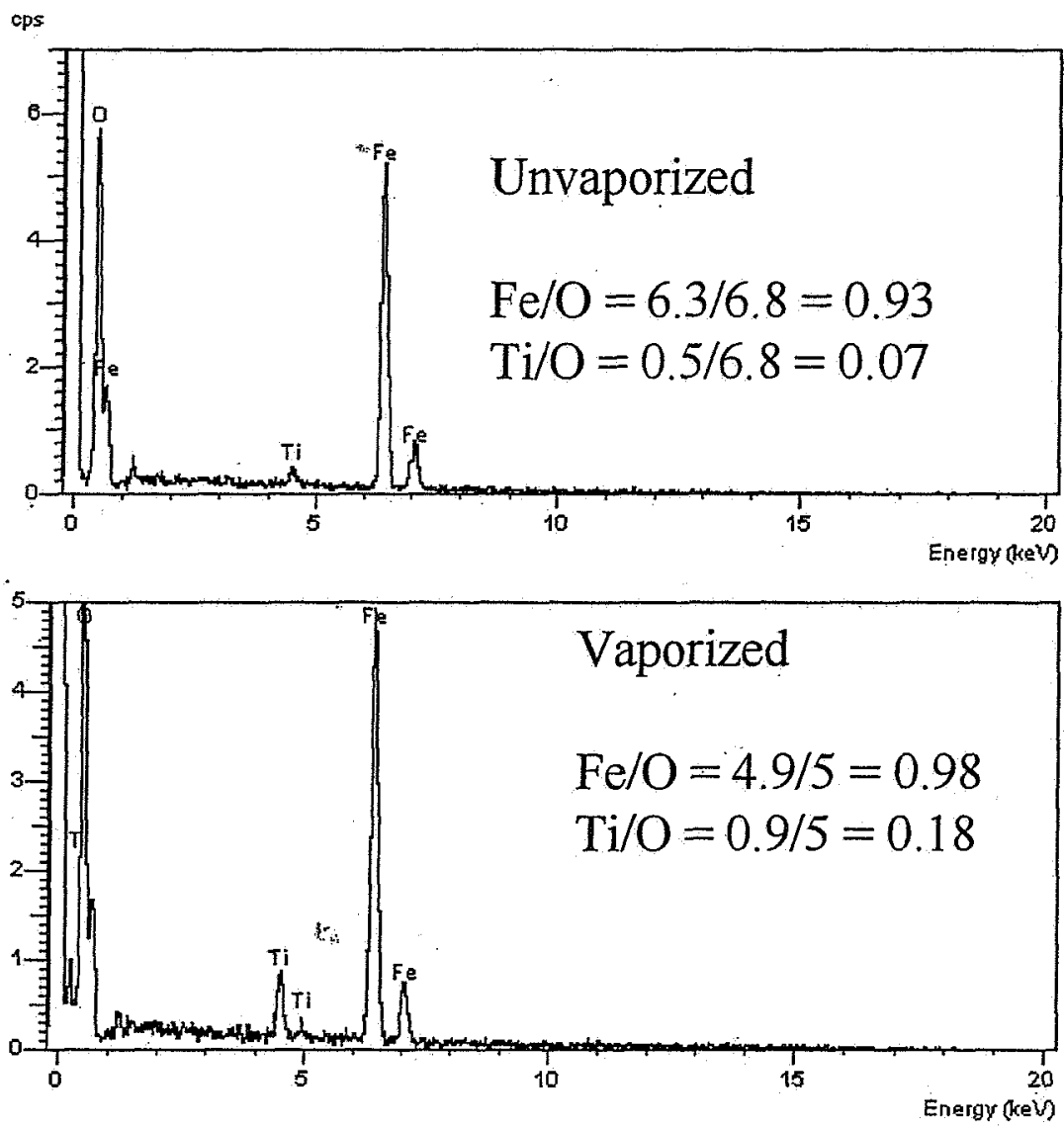

Figure 5. Relative counts per second for an ilmenite sample before and after testing in the prototype system, indicating a relative depletion of oxygen in the partially vaporized sample. The higher ratios of iron and titanium to oxygen indicate reduced oxygen in the surface of the remaining material.

\section{MODELING}

The results shown in Table 1 were inconsistent with the expected temperatures required for vaporization in previous work (Steurer, 1985; Senior, 1993). Modeling of the chemistry of the vaporization/dissociation was performed via minimization of the Gibbs free energy with the HSC analysis package to determine the cause of this disparity. Equilibrium chemistry was used to show that the vacuum level has a substantial effect on the required vaporization temperature. The equilibrium composition of vaporized MLS-1A is shown in Figures 6 and 7 for pressures of $10^{-1}$ and $10^{-7}$ Torr, respectively. As the pressure is reduced in Figure 7, the vaporization temperature is shifted to the left. 


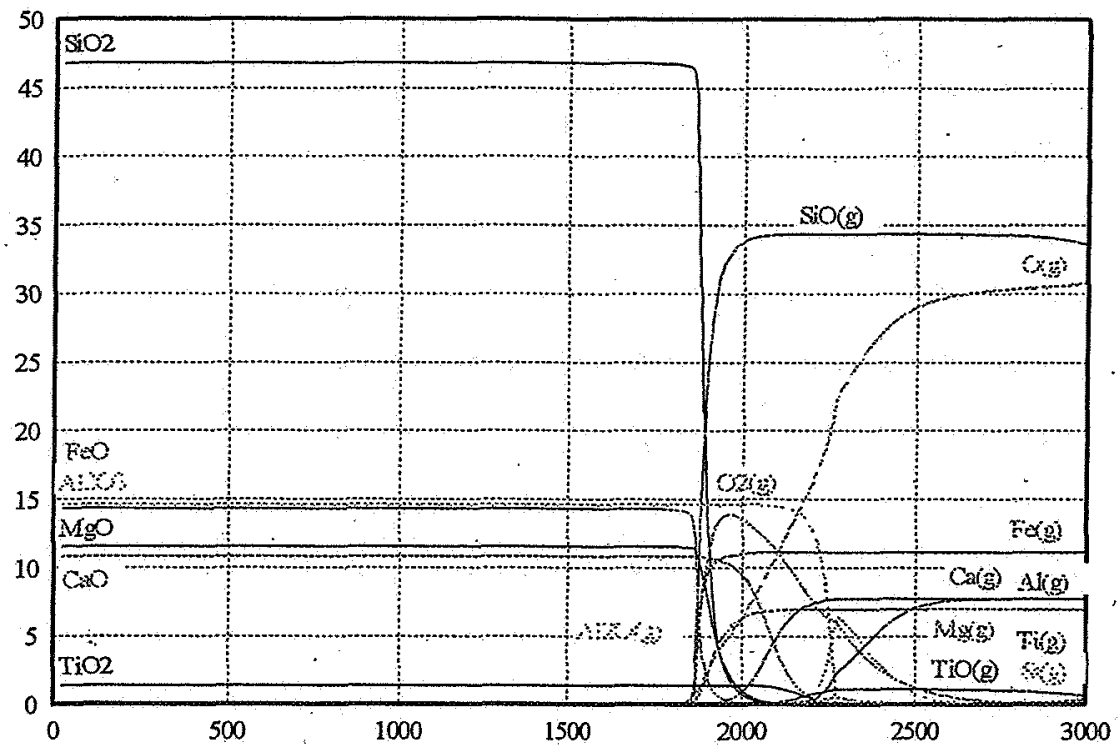

Figure 6. Equilibrium composition (by percent composition) of a sample of MLS-1A at $10^{-1}$ Torr.

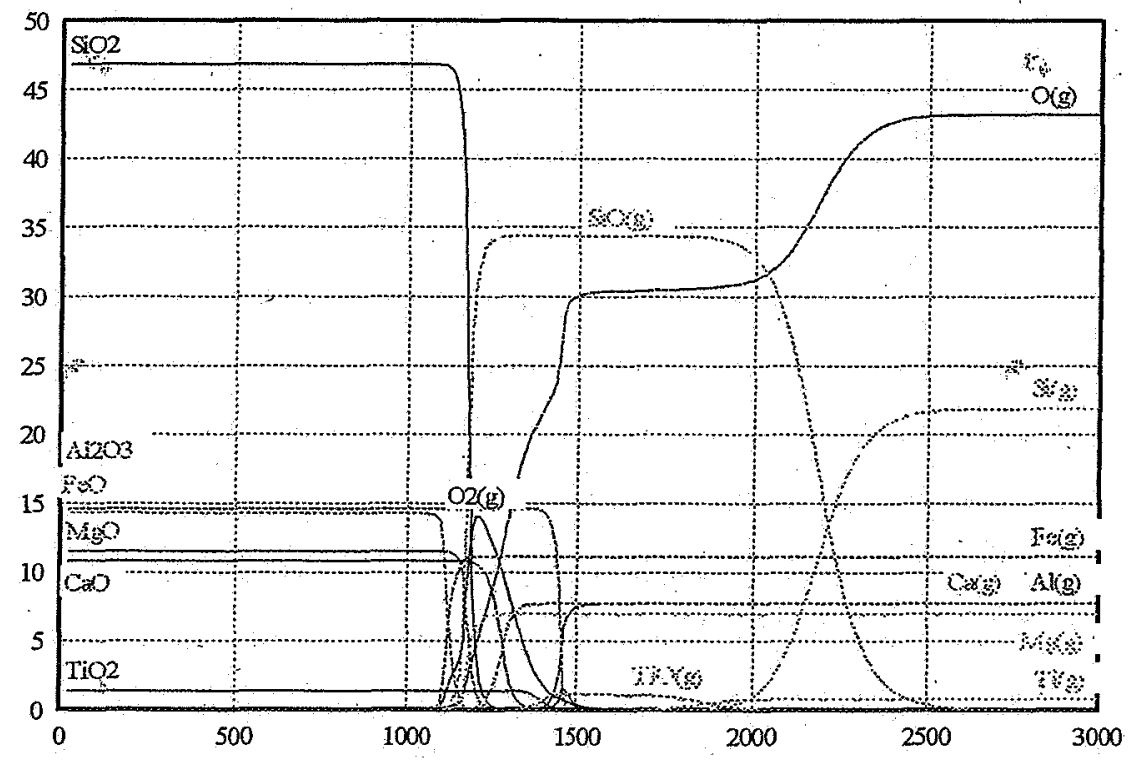

Figure 7. Equilibrium composition (by percent composition) of a sample of MLS-1A at $10^{-7}$ Torr.

\section{REDUCEDD PRESSURE TESTING}

Proof-of-principle tests were conducted at the Pennsylvania State University Sintering Lab to verify these analytical predictions in a high-temperature vacuum furnace. Samples of $\sim 10 \mathrm{~g}$ of MLS-1A were completely vaporized, as illustrated in Figure 8. In addition, tests were conducted at slightly lower temperature that showed no vaporization. These points bracket the model curve, as illustrated in Figure 9. The vaporization temperature drops to the temperatures commonly used for ilmenite reduction for pressures below $\sim 10^{-5}$ Torr. It is useful to note that the ambient conditions on the lunar surface are far to the left. A vacuum pyrolysis processing plant on the lunar surface would operate around $10^{-7}$ Torr, assuming an enhanced background pressure due to human activity, and that the oxygen is cryo-pumped out of the chamber at approximately the same rate as the gas formation, 
Sintering was also observed at conditions that approached vaporization. The sintering was particularly pronounced for tests with ilmenite samples.
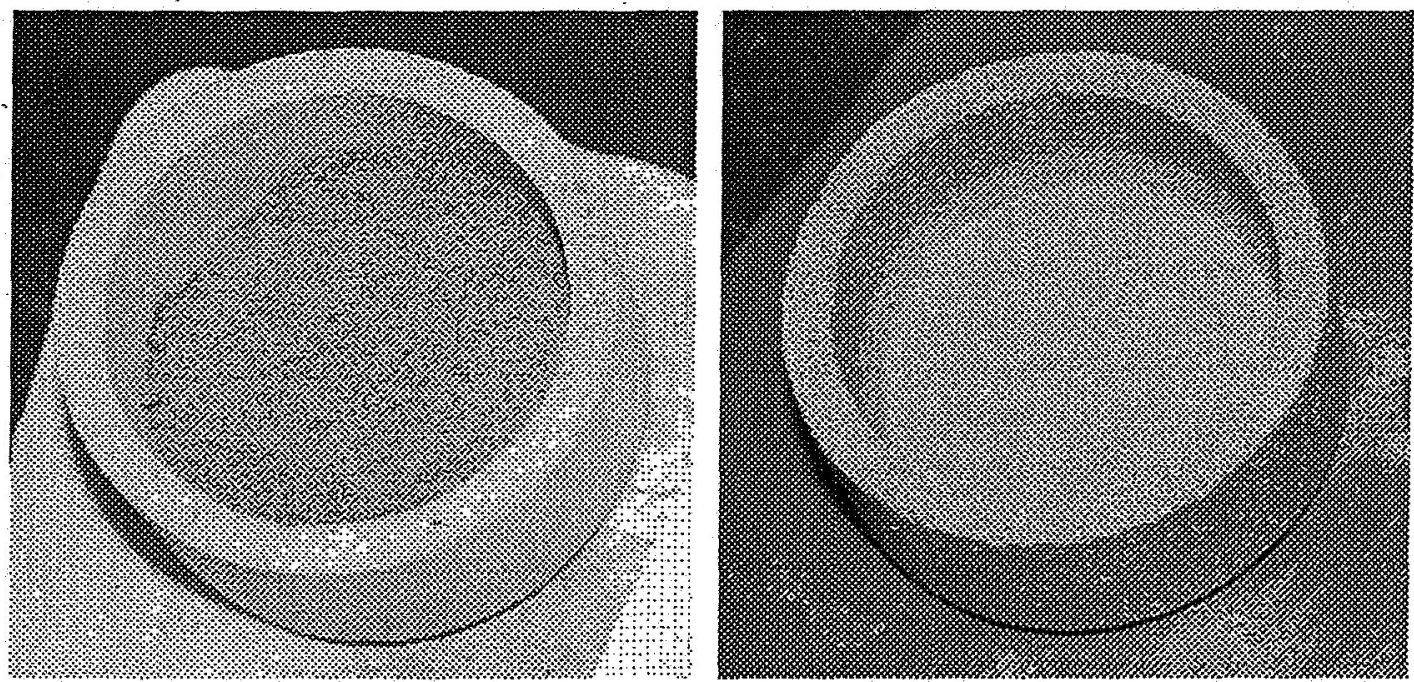

Figure 8. Crucible before (left) and after (right) pyrolysis in vacuum to $10^{-5} \mathrm{Torr}$ and $1400^{\circ} \mathrm{C}$ at PSU. The vaporized material was $10 \mathrm{~g}$ of MLS-1A lunar simulant.

ris

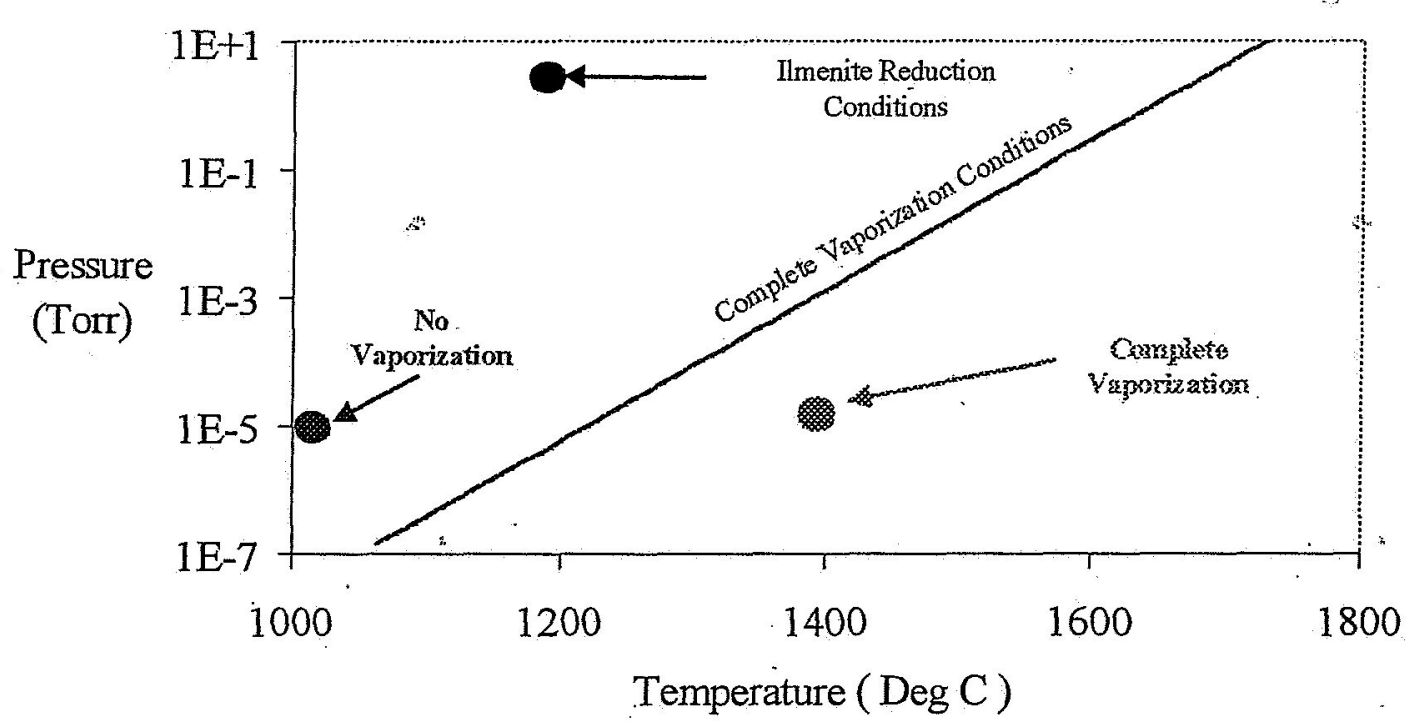

Figure 9. System pressure and temperature required to vaporize an Apollo 11 soil simulant (MLS-1A is derived from a hightitanium basalt that approximates the chemical composition of Apollo 11 soil).

\section{RESISTIVE HEATING CHAMBER}

The significant reduction of temperature required for vacuum pyrolysis indicates that the high temperatures that can be produced in a solar furnace are not required, though it may be useful for production of oxygen on a larger scale. Ilmenite reduction is commonly performed with relatively simple resistive heating systems. A system for resistive heating to perform vacuum pyrolysis has been designed and produced at NASA GSFC. A picture of this system is shown in Figure 10. 


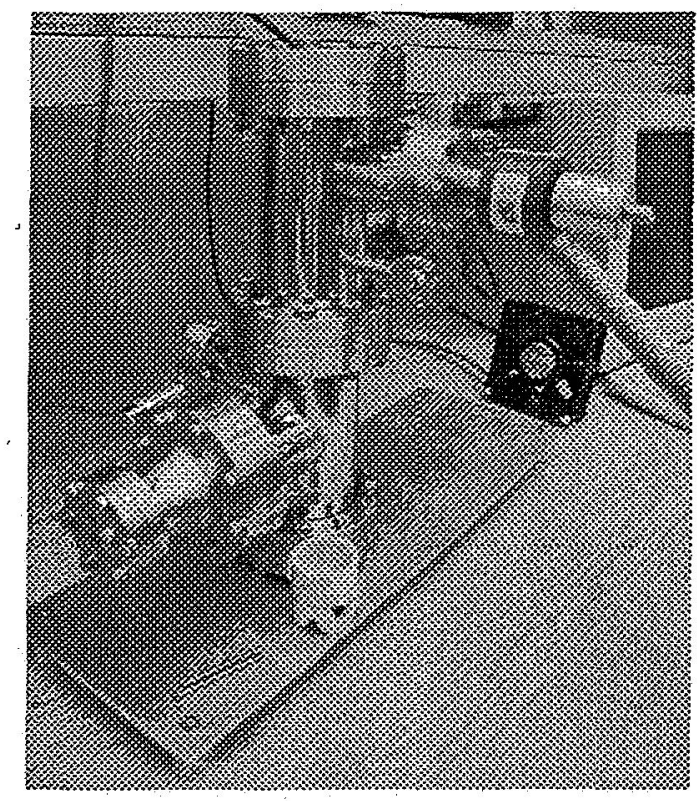

Figure 10. Prototype setup for resistive heating of lunar regolith in vacuum. r:

\section{CONCLUSIONS}

Several different techniques have been pursued at NASA GSFC to advance the state of the art of in situ resource utilization. Although most of these techniques were applied to vacuum pyrolysis, many of the techniques established as part of this work are applicable to other processes. Large power fluxes, such as those provided by the reflector, can be used for heating of any of the oxygen production techniques. Sintering and melting of the regolith can be used for making bricks of consolidated suiffaces. These techniques have all been used to demonstrate the production of oxygen via vacuum pyrolysis. The prototype Fresnel system demonstrated the production of small quantities of oxygen, and a larger resistive heating system demonstrated vaporization of samples of 10 grams. Further work will pursue more accurate investigations of the chemistry in a resistively-heated chamber that is not susceptible to changes in the solar flux, and a larger solar flux system to demonstrate the vaporization of larger quantities of simulant.

\section{ACKNOWLEDGMENTS}

This work was made possible by internal support from NASA GSFC. The authors would like to acknowledge the assistance of Lt. John Matchett, USAF, with much of this work.

\section{REFERENCES}

Cardiff, E., Pomeroy, B., and J. Matchett, "The Vacuum Pyrolysis Technique of In Situ Oxygen Production", LEAG / Space Resources Roundtable Meeting, October, 2005.

Griffin, M., NASA Headquarters News Conference to Release the Exploration System Architecture Study Results, September $19,2005$.

Senior, C., "Lunar Oxygen Production by Pyrolysis", Resources of Near Earth Space, The University of Arizona Press, Tuscon, 1993.

Steurer, W., "Vapor Phase Pyrolysis", In Space Manufacturing, 1985.

Weiblen P.W., Murawa M.J., and Reid K.J. "Preparation of simulants for lunar surface materials"; Engineering, Construction and Operations in Space II, American Society of Civil Engineers, New York, pp. 428-435, 1990. 